\title{
REVIEW
}

\section{Development of conservation strategies to mitigate the bycatch of harbor porpoises in the Gulf of Maine}

\author{
Andrew J. Read* \\ Division of Marine Science and Conservation, Nicholas School of the Environment, Duke University, Beaufort, \\ North Carolina 28516, USA
}

\begin{abstract}
In this paper I review the development of conservation strategies to address the bycatch of harbor porpoises Phocoena phocoena in Gulf of Maine gillnet fisheries from 1982, when bycatches were first detected, until a Take Reduction Plan was implemented in 1999. After consideration of several mitigation options, the plan included a combination of time-area closures and the use of acoustic alarms. Implementation of these measures reduced the annual bycatch of porpoises from a high of 2900 in 1990 to 323 in 1999, the first year in which bycatches fell below the potential biological removal (PBR) level. The success of these measures can be attributed to several factors, including a clear conservation goal, the PBR level, mandated by the US Marine Mammal Protection Act. The importance of PBR is underscored by contrasting experiences in the USA, where the goal was achieved, and those in Canada, where no comparable goal existed and no conservation measures were implemented. The availability of detailed scientific information on bycatch levels and abundance was critical to persuading all stakeholders of the need to act. Successful negotiation within the Take Reduction Team was facilitated by a long prior history of informal collaboration and dialogue. Finally, the monitoring program provided important feedback on the efficacy of measures in reducing bycatch, effectively closing the loop on the management process. This case study is instructive in several regards with respect to the elements necessary to address bycatch issues involving small cetaceans and gillnet fisheries.
\end{abstract}

KEY WORDS: Harbor porpoise $\cdot$ Bycatch $\cdot$ Gillnets $\cdot$ Gulf of Maine

Another feature of the net fishing is that, in addition to the various species of Gadidae which have been taken, porpoises (locally called 'puffers') ... have been caught ...

J. W. Collins (1886, p. 283)

\section{INTRODUCTION}

Spencer Baird, first Commissioner of the United States Fish Commission, introduced gillnets to the United States in the winter of 1880. At that time, gillnets were being used in Norway and New- foundland, but fishermen in the USA were using baited hand lines to catch cod Gadus morhua. Commissioner Baird asked cod fishermen from Gloucester, Massachusetts, to test this new fishing gear, and the fishermen found the nets to be highly effective. In a report describing the results of the initial trials, Collins (1886) described an added benefit to fishermen - gillnets occasionally captured 'puffers,' or harbor porpoises Phocoena phocoena, which could be used for food and bait. Today, gillnets are a popular fishing gear throughout the world because of their low cost, simplicity, flexibility and size selectivity for target species. 
For more than a century since bottom-set gillnets were introduced to the Gulf of Maine, harbor porpoises have proven exceptionally vulnerable to entanglement in this fishing gear (Fig. 1). Thousands of harbor porpoises are also killed elsewhere each year in gillnet fisheries throughout the northern hemisphere (Jefferson \& Curry 1994). This mortality has exceeded sustainable levels in several areas, and, as a result, considerable research has been devoted to this problem. In this paper, I describe the bycatch of harbor porpoises in gillnet fisheries in the Gulf of Maine, USA, and review conservation actions taken to address the problem from its initial discovery to the implementation of the Take Reduction Plan in 1999. I use the road map described by Read (2010) to structure the review. The rather depressing story from 1999 onwards is taken up by a companion paper in this Theme Section (Orphanides \& Palka 2013).

I hope the story of harbor porpoise bycatch in the Gulf of Maine will be instructive to those working on

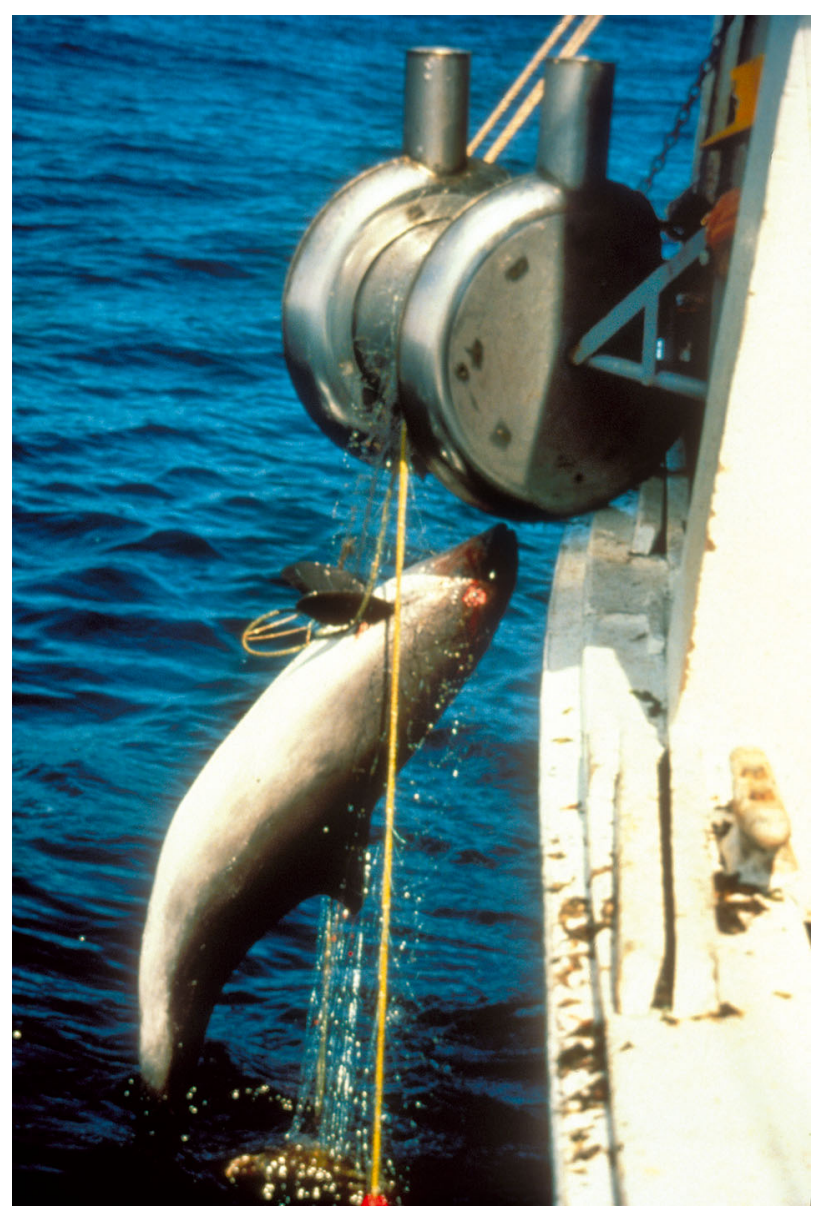

Fig. 1. Phocoena phocoena. Harbor porpoise entangled in a bottom-set gillnet on Jeffrey's Ledge, New Hampshire, USA, in April 1988. Photograph by Bill Eppridge bycatch issues elsewhere, particularly where species at greater conservation risk are involved. I have argued elsewhere (Read 2010) that many conservation issues follow a similar progression. The lessons learned in the Gulf of Maine concerning the importance of a clear conservation goal, adequate information, the involvement of stakeholders and a postimplementation monitoring program may be widely applicable. Obviously not everything learned in the Gulf of Maine will be relevant in every case, particularly in situations where an appropriate management structure and adequate resources are lacking, but even under such circumstances, some of the history of this issue in the Gulf of Maine should be instructive.

Harbor porpoises are among the smallest cetaceans, seldom exceeding $1.6 \mathrm{~m}$ in length and $70 \mathrm{~kg}$ in mass (Read 1999). They are distributed throughout coastal waters of the boreal northern hemisphere (Gaskin 1984), which include some of the most heavily fished areas of the world (e.g. Pauly \& Maclean 2003). Harbor porpoises in the Gulf of Maine feed on small schooling fishes, particularly herring Clupea spp. and small gadids (Gannon et al. 1998). These small fish are also the prey of commercially valuable species, such as cod, dogfish Squalus spp. and pollock Pollachius virens, that are the targets of bottomset gillnet fisheries.

For such small animals, harbor porpoises possess a remarkable diving ability. Individuals equipped with time-depth recorders have reached the deepest portions of the Bay of Fundy, with some dives exceeding $200 \mathrm{~m}$ (Westgate et al. 1995). Captive and wild porpoises have been observed foraging on prey very near the sea floor and sometimes even on fish buried in soft sediments. It is not surprising, therefore, that harbor porpoises encounter bottom-set gillnets frequently.

Harbor porpoises are not much larger than the target species of many gillnet fisheries in which they become entangled. Once entangled in bottom-set gillnets, most porpoises die of asphyxiation after a few minutes of struggle. There is little, if any, damage to the gear, so there are few direct financial incentives for a fisherman to reduce the number of animals killed in this manner.

During summer, harbor porpoises are found primarily in the northern Gulf of Maine and Bay of Fundy (Fig. 2; Waring et al. 2011). In autumn, porpoises expand their range south into the Gulf of Maine (Read \& Westgate 1997) and some individuals overwinter along the mid-Atlantic coast of the USA. These seasonal movements reflect their pref- 


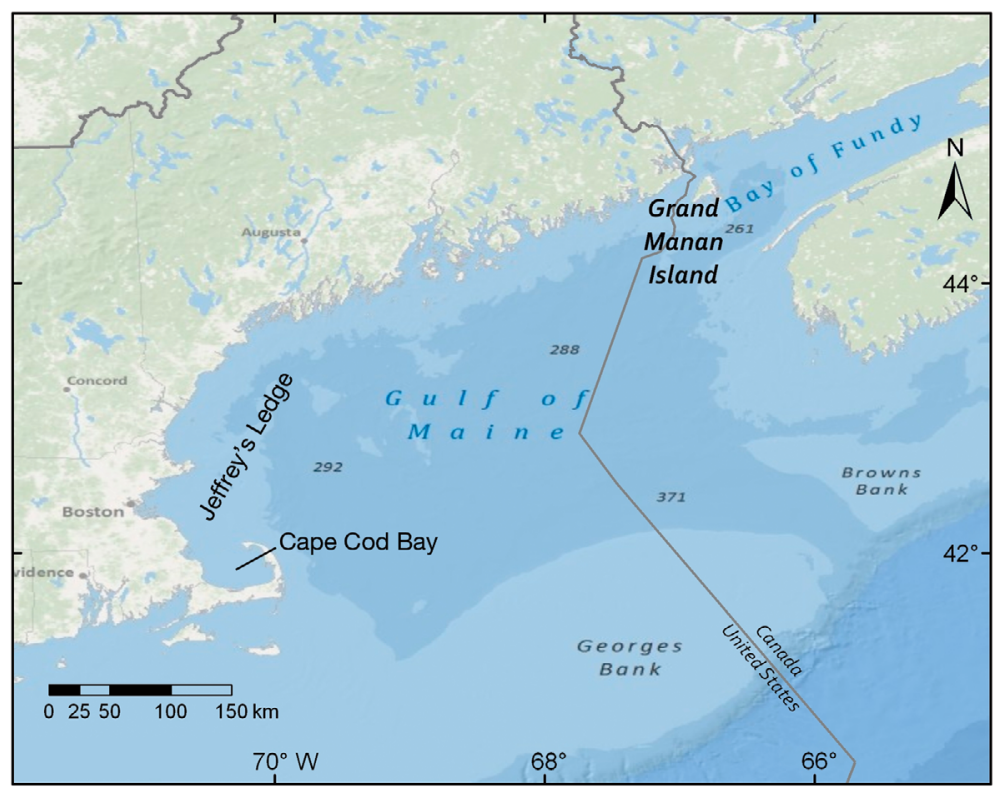

Fig. 2. Gulf of Maine showing depth $(\mathrm{m})$ and place names mentioned in the text

erence for cold waters and the seasonal migrations of their prey, particularly herring, in the Gulf of Maine.

Several lines of evidence, including nuclear and mitochondrial genetic markers (Rosel et al. 1999), movement patterns (Read \& Westgate 1997) and contaminant levels (Palka et al. 1995), indicate that harbor porpoises in the Bay of Fundy and Gulf of Maine comprise a discrete population. As a result, this population of porpoises is managed as a single 'stock' under the Marine Mammal Protection Act (MMPA) in the USA (Waring et al. 2011). There is no counterpart to the MMPA in Canada, but porpoises move freely across the Hague Line that separates the waters of the United States and Canada (Fig. 2).

In the Gulf of Maine, gillnets are set on the sea floor to catch large cod, other gadids and dogfish (referred to together as groundfish). Individual nets (each approximately $90 \mathrm{~m}$ in length) are joined at their ends by bridles, forming 'strings' of up to 20 nets. Due to the strong tidal currents in the Bay of Fundy, Canadian fishermen typically fish shorter strings (Read \& Gaskin 1988). The nets are fished for at least $24 \mathrm{~h}$ before being hauled and re-set; some nets may be fished continuously for several days. Strings of gillnets are anchored at each end and marked at the surface with buoys and radar reflectors (Fig. 3).

The basic design of any gillnet is quite simple, with mesh webbing strung between a buoyant, upper head line and a lower, weighted lead line. The fish- ing performance of these nets can be modified by changing mesh size, twine diameter and/or hanging ratio. The mesh size of gillnets varies with the size of the target species; in the Gulf of Maine most nets are from 140 to $178 \mathrm{~mm}$ stretched mesh, although larger mesh sizes are occasionally used. The nets are constructed of monofilament, with a twine diameter of approximately $0.6 \mathrm{~mm}$. The hanging ratio (the ratio between the length of the head line and the length of the stretched netting) is typically 0.5, although this can be varied to make the netting more or less taut. All of these factors may affect the likelihood that a net will entangle a porpoise.

In addition, some nets are modified to catch fish that are closely associated with the sea floor, such as flatfish and monkfish Lophius spp. In these nets a series of 'tie-down' lines connect the head and lead lines of the net, forming a long bag of net that extends along the bottom. Tie-down nets may be left to fish for many days, because captured fish may live for relatively long periods.

Vessels in the Gulf of Maine gillnet fishery are relatively small (10 to $17 \mathrm{~m}$ ) and are typically operated by their owners. Most boats fish in day trips with a crew of 2 or 3, although a small number of vessels may fish offshore grounds in trips that last several days. Most gillnets are set in depths between 50 and $100 \mathrm{~m}$. In 2007, > 300 vessels reported using sink gill-

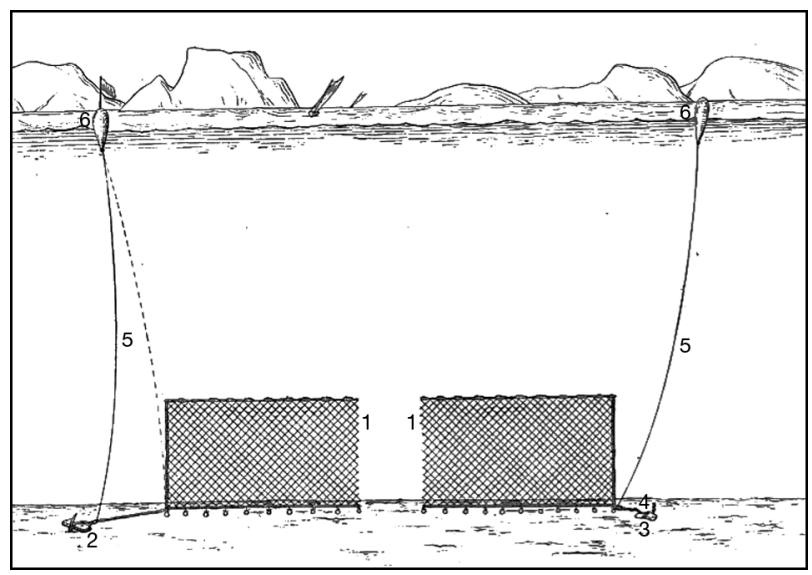

Fig. 3. Bottom-set gillnets used in the Gulf of Maine in 1880. Little has changed in the basic architecture of this fishing gear since that time, although modern materials, including monofilament mesh and synthetic fiber lines, are now used. Image taken from Collins (1886). 1: net; 2, 3: anchors; 4: anchor line; 5 : float line; 6 : surface float 
nets in the Gulf of Maine (Waring et al. 2011); the number of active vessels in the Bay of Fundy is much lower, perhaps only a few tens of vessels.

\section{INITIAL DETECTION OF THE PROBLEM}

Concern was first expressed over the conservation status of harbor porpoise populations in the mid1970 s, when large bycatches of this species were observed in salmon drift nets in West Greenland (Lear \& Christensen 1975). Gaskin (1984) reviewed knowledge of the regional status of the species and underscored concerns about the sustainability of bycatches in many areas.

In 1982 Jim Gilbert and Kate Wynne began to investigate marine mammal bycatches in the gillnet fishery along the coast of Maine by conducting interviews, providing logbooks to fishermen, and accompanying them on a small number of trips. Gilbert \& Wynne (1988) estimated that, on average, each fisherman caught 5.1 porpoises annually. At the time, Gilbert and Wynne believed that it was unlikely that this bycatch rate was typical for the entire fleet.

In addition, there were reports of large bycatches of porpoises each autumn on Jeffreys Ledge, off the coast of New Hampshire (Gaskin 1984). Together with the data obtained by Gilbert and Wynne, these early anecdotal reports suggested that several hundred porpoises could be killed each year. The existence of a large bycatch was confirmed when a Sports Illustrated writer and photographer observed a bycatch of 7 harbor porpoises in the nets of a gillnet vessel fishing on Jeffreys Ledge in April 1988 (Hoyt 1989; my Fig. 1).

At about the same time, David Gaskin and I began an investigation into the bycatch of harbor porpoises in the Canadian gillnet fishery in the Bay of Fundy. We started this work in 1985 to obtain carcasses for a study of the life history of harbor porpoises. We offered \$25 (Canadian) for any porpoise killed in fishing gear and were soon swamped by the large number of dead porpoises provided by gillnet fishermen. The supply rapidly outpaced our ability to process the carcasses, and we were forced to store dead harbor porpoises on ice in the cellar of our small research station on Grand Manan Island.

In 1986 we obtained funding from the Canadian Department of Fisheries and Oceans (DFO) to examine the magnitude of the porpoise bycatch. We conducted phone interviews with fishermen at the end of the fishing season, who reported catching 5.5 porpoises each, yielding an estimate of 105 porpoises taken that year (Read \&Gaskin 1988). We obtained 56 porpoise carcasses through the reward program. There was remarkable concordance between our observations and those of Gilbert and Wynne on the other side of the border.

The preliminary results of this work suggested that perhaps 700 porpoises were being taken annually in the gillnet fisheries of the Gulf of Maine and Bay of Fundy. These were very rough estimates to be sure, but it was clear that the bycatch was substantial.

In the early 1980 s, there was little regional or national focus on the management of harbor porpoise bycatch in either Canada or the USA. Managers in eastern Canada were preoccupied with the hunt for harp seals Pagophilus groenlandicus, while their counterparts in the eastern USA were addressing the bycatch of pilot whales Globicephala melas and common dolphins Delphinus delphis in mid-water trawl fisheries for mackerel Scomber scombrus and squid Loligo and Ilex spp.

The bycatch of harbor porpoises in the USA was authorized by a small-take exemption provision in the MMPA, obtained by the University of Maine in 1984 on behalf of the gillnet fleet. This permit allowed the bycatch of 180 animals $\mathrm{yr}^{-1}$. It was clear that actual removals exceeded this level (Gilbert \& Wynne 1988), and the issue of porpoise bycatch was about to become a significant regional and national concern (Burrowes 1988, Hoyt 1989, Polacheck 1989).

\section{INDUSTRY RESPONSE}

The initial response of the fishing industry to the detection of large bycatches of harbor porpoises was to take issue with the estimates and their potential impact. For example, in a letter sent to the Director of the National Marine Fisheries Service (NMFS) Office of Protected Resources, Ted Ames, President of the Maine Gillnetters Association, suggested that Gaskin and I had 'unwittingly created a market for porpoise' on Grand Manan by paying \$25 (Canadian) for each dead animal, thus influencing fishing patterns and bycatch rates of gillnet fishermen. This seemed unlikely, as we had obtained only 56 carcasses from 19 vessels, yielding an average supplement of $<\$ 75$ (Canadian) per vessel. Ames also suggested that Gilbert and Wynne's study was flawed because fishermen were more likely to respond to requests for information if they had caught porpoises and, furthermore, the areas Gilbert and Wynne had sampled were rarely fished any more. 
Fishermen and their representatives also took issue with estimates of the population size of harbor porpoises available at that time. They pointed out that porpoises appeared to be much more abundant than suggested by the results of initial surveys, which indicated a population of perhaps 15000 (Kraus et al. 1983). This view proved to be correct once more complete surveys were conducted (see next section).

However, the response of the fishing industry was not entirely negative. In 1990, several gillnet fishermen and their representatives from New England (including Ames) began meeting informally with fisheries managers, scientists and representatives of environmental organizations. These meetings were initiated by Bob Mackinnon, a gillnet fisherman from Scituate, Massachusetts, and David Wiley, from the International Wildlife Coalition. An informal group developed to facilitate dialogue regarding fishing practices and harbor porpoise biology and to explore (and argue over) possible mitigation measures. The group's purpose was 'to define the extent of problems and identify solutions pertaining to harbor porpoise and commercial fisheries interactions in the Gulf of Maine, and more specifically, to reduce the incidental take of harbor porpoise in gillnets' (D. Wiley, Stellwagen Bank National Marine Sanctuary, pers. comm.). This informal coalition became known as the New England Harbor Porpoise Working Group (hereafter 'Working Group') and was to play a pivotal role in the development of conservation measures to reduce the bycatch of harbor porpoises in the Gulf of Maine. Members of the group agreed to disagree about many issues and, importantly, only took action when a consensus was achieved. Gillnet fishermen were instrumental in these discussions and, as described below, played a leading role in the search for solutions.

\section{ASSESSMENT OF IMPACT}

In 1988, the MMPA was amended to include an Exemption Program to facilitate the assessment of marine mammal bycatch in commercial fisheries (Burrowes 1988). Commercial fisheries were classified as to their likelihood of taking marine mammals as bycatch; participants in fisheries with frequent bycatch were required to carry federal observers as a condition of their permits. The NMFS began to place observers aboard gillnet vessels in the Gulf of Maine in 1989. These observers recorded the number of porpoises entangled in each net, together with relevant information on the location and configuration of the net, and the number of fish captured and retained. Between June 1989 and May 1991 observers monitored 289 fishing trips (about $1 \%$ of the total) and documented 34 porpoises taken as bycatch (Smith et al. 1991). The observer program has continued to this day, with 2 to $6 \%$ of fishing trips monitored each year (Waring et al. 2011, Orphanides \& Palka 2013).

Data collected by observers allowed estimation of a bycatch rate for this fishery. To estimate total bycatch, this observed rate must be extrapolated to the entire fishery, using some measure of total fishing effort. Estimation of fishing effort in this and other gillnet fisheries has proven to be problematic. The NMFS has used landings (i.e. tons of fish landed) as a metric of effort in this fishery, in the absence of a more precise measure (such as kilometer hours of nets fished). Effort data are very difficult to obtain from gillnet fisheries, because participants do not keep accurate records of the requisite information. By combining estimates of the observed bycatch rate with total landings, NMFS biologists were able to generate estimates of the magnitude of harbor porpoise bycatch in the Gulf of Maine. The initial findings were alarming, with 2900 porpoises $(\mathrm{CV}=0.32)$ estimated to have been taken in 1990 (NEFSC 1994).

At that time there had been only a single, incomplete survey of the harbor porpoise population in the Gulf of Maine and little information existed on population structure. This survey, conducted in 1981, indicated a population of approximately 15000 harbor porpoises (Kraus et al. 1983). Taken together, therefore, this early research suggested that bycatches were removing approximately one-fifth of the population annually.

With preliminary, albeit somewhat crude, estimates of abundance and bycatch now available, scientific attention turned to the population's ability to withstand such removals. No empirical estimates of the potential population growth rate were available for this species, so researchers attempted to model its rate of increase. Models of potential population growth require estimates of both fecundity and survival. Estimates of fecundity were available from our observations of dead porpoises from the Bay of Fundy (Read 1990). Female harbor porpoises reach sexual maturity relatively early (typically at Age 3 or 4) and most become pregnant and give birth each year. As is the case for most other marine mammals, however, harbor porpoises give birth to a single offspring per pregnancy, thus limiting their potential rate of increase. 
Unfortunately, there were no estimates of age- or stage-specific survival rates to use in these demographic models. We knew that, compared to many other odontocetes, harbor porpoises are relatively short-lived, and we had estimates of the ages of porpoises killed in Bay of Fundy gillnets, but this sample was biased due to age-specific variation in capture probability. Small calves seldom dive to the sea floor, so they were under-represented in the sample. In contrast, juvenile animals appeared to be over-represented, perhaps due to their inexperience in foraging around nets.

Two early attempts were made to model potential rate of increase for harbor porpoises using age-specific survival rates from other mammals. Barlow \& Boveng (1991) combined survival estimates from northern fur seals Callorhinus ursus, Old World monkeys and humans, with fecundity data from harbor porpoises. Only the human survival data set produced a positive population growth rate, with a value of $9.4 \% \mathrm{yr}^{-1}$. Woodley \& Read (1991) used a similar approach, employing survival data from Himalayan thar Hemitragus jemlahicus, an ungulate with a life history similar to that of the harbor porpoise. Woodley and Read concluded that the harbor porpoise population in the Gulf of Maine was unlikely to sustain incidental mortality rates exceeding $4 \%$ of the population per year. Neither modeling approach was very satisfactory, because the choice of the species used to provide the survival schedule dictated the outcome of the exercise. It was clear that harbor porpoise survival schedules did not resemble those of humans, but it was not clear whether the Himalayan thar was a reasonable substitute.

\section{INITIAL MANAGEMENT ACTIONS}

The Scientific Committee of the International Whaling Commission (IWC) reviewed the status of harbor porpoise Phocoena phocoena populations in 1990 (IWC 1991). In its review of the situation in the Gulf of Maine, the Committee concluded that 'current levels of incidental mortality pose a serious threat to the harbor porpoise sub-population in this area' and recommended that 'steps be taken to reduce the incidental mortality of harbor porpoises in this region.'

The United States Marine Mammal Commission, which provides independent oversight of the policies and programs carried out by federal regulatory agencies, wrote to the NMFS in October 1990 advising it that bycatch could be having a significant adverse impact on the harbor porpoise population in the Gulf of Maine (MMC 1992). The Commission also noted that the USA should develop a coordinated research and management plan with Canada.

In September 1991 a coalition of environmental groups petitioned the NMFS to list the harbor porpoise population in the Gulf of Maine as 'threatened' under the US Endangered Species Act (ESA). The NMFS had already added the population to its list of candidate species for listing, and in December, after agreeing that the petition presented substantial information, the agency began a status review (NMFS 1991). The proposal to list this population was a powerful motivating force for fishermen to work with scientists and conservation groups to reduce the bycatch of porpoises in the gillnet fishery. Commenting on the petition, William Fox, the Assistant Administrator of the NMFS, referred to the bycatch of harbor porpoises in the Gulf of Maine as 'the most significant marine mammal ... problem in the nation' (D. Dumanoski, Boston Globe, 1 Jan 1991). Two years later, following a workshop reviewing the status of the population (NMFS 1992), the NMFS proposed to list the harbor porpoise population in the Gulf of Maine as threatened under the ESA (NMFS 1993).

At the same time, 2 other management processes were underway that would have a profound effect on this issue. The first was the re-authorization of the MMPA. A decision of the US Court of Appeals for the D.C. Circuit (Kokechik Fishermen's Association vs. Secretary of Commerce) had called into question the way that the NMFS issued incidental take permits for marine mammals killed in commercial fishing operations (Burrowes 1988). As a result, a coalition of environmental groups negotiated a compromise approach with representatives of several commercial fisheries, but not including the Gulf of Maine gillnet fleet. This compromise allowed the NMFS to collect baseline information on marine mammal populations and their interactions with commercial fisheries, while developing a comprehensive management strategy for dealing with these removals. In 1988 the MMPA was amended to provide a 5 yr exemption to the prohibition of taking marine mammals in commercial fisheries. This provided a window of time for the gillnet fishery to explore ways to reduce the bycatch of harbor porpoises before management actions were required. The MMPA was re-authorized again in 1994, when the current regime of dealing with marine mammal bycatch was adopted, including the formal stock assessment and take reduction processes (see 'Implementation').

At the same time there was a bitter debate regarding management of groundfish in the Gulf of Maine. 
This fishery is managed by the New England Fishery Management Council (NEFMC), which implements the Magnuson-Stevens Fishery Conservation and Management Act. The Council was struggling to address the over-harvest of groundfish stocks in the Gulf of Maine (see Dobbs 2000) and considering a variety of conservation measures, including effort reduction, trip limits, gear modifications and area closures. In October 1992, as it considered these options, the Assistant Administrator of the NMFS asked the Council to take action to reduce the bycatch of harbor porpoises in the Gulf of Maine. The Council convened a group of advisors (known as the Marine Mammal Subgroup) to its Groundfish Plan Development Team to deal with harbor porpoise bycatch.

There was also management activity in Canada, although not to the same extent as in the United States. In April 1990 the Committee on the Status of Endangered Wildlife in Canada (COSEWIC) assessed and designated the harbor porpoises in eastern Canada as threatened, citing bycatch as the principal threat (Gaskin 1992). This designation did not carry the same weight as a listing under the United States ESA, because there was no legislative mandate requiring conservation actions as a consequence of the decision. Nevertheless, shortly thereafter the Canadian DFO convened a Harbor Porpoise Recovery Team to address the bycatch of harbor porpoises in the Bay of Fundy. The team held its first meeting in 1991, attended by fishermen, researchers, managers and representatives of environmental groups.

Thus, by 1992, considerable resources were being directed at the bycatch of harbor porpoises in the Gulf of Maine and Bay of Fundy. The NMFS was conducting surveys to refine estimates of abundance, rplacing observers aboard fishing vessels to estimate bycatch, and supporting research on the biology of the species (NMFS 1992). The Working Group, the NEFMC and the Canadian Harbor Porpoise Recovery Team were independently considering and evaluating potential mitigation strategies.

\section{THE SEARCH FOR SOLUTIONS}

\section{Time-area closures}

The NEFMC Marine Mammal Subgroup considered a variety of bycatch mitigation options that could be integrated with measures designed to conserve groundfish stocks. The Council adopted a $4 \mathrm{yr}$ goal of reducing the bycatch of porpoises to no more than $2 \%$ of estimated abundance, following provisional advice from the IWC Scientific Committee (IWC 1991). The initial mitigation options considered by the Subgroup included monthly closures of the fishery for $4 \mathrm{~d}$ periods (a default option designed to reduce fishing effort), gear modifications, restrictions on the number of nets used per vessel and a system of time-area closures. The monthly $4 \mathrm{~d}$ tie-up periods and time-area closures were unpopular with fishermen, who preferred gear modifications and caps on the number of nets used.

Data on the spatial and temporal distribution of bycatches from the NMFS observer program were provided to the Subgroup by the NEFSC (Fig. 4). These observations indicated a strong seasonality in the distribution of bycatches, reflecting the seasonal movements of harbor porpoises in the Gulf of Maine. Large bycatches occurred on Jeffreys Ledge (hereafter referred to as the Mid-Coast) in autumn, along the northeastern coast of Maine (northeast) during summer and in Massachusetts Bay in spring. The strong seasonality of these bycatches persuaded the Subgroup to pursue the option of time-area management so mitigation measures could be focused on areas with high bycatches. There was no scientific basis with which to predict the effect of reducing the number of nets used per vessel, and time-area closures were easier to enforce than limits on the total number of nets. Vessels fishing in closed areas could be detected readily by the US Coast Guard during their regular enforcement over-flights or by patrol vessels.

The initial discussions of seasonal time-area closures focused on data aggregated at a relatively coarse level: the statistical area used to report effort and catches (Fig. 4). In its deliberations the Subgroup agreed to prioritize measures that imposed the least cost on the fishery with an equitable distribution of cost amongst fishery participants. In practical terms, this meant designing closures that were as small and short as feasible and did not result in the redistribution of fishing effort. It quickly became clear that it would be desirable to work at a finer scale than large statistical areas.

To explore a more parsimonious closure system analysts from the NEFSC developed a Geographic Information System (GIS) that combined data collected from the observer program (porpoise bycatches and observed fish catches) and information on landings collected during shore-based port sampling. This analysis was performed in 30 min squares of latitude and longitude, making it possible to predict porpoise bycatch and landings in each stratum 


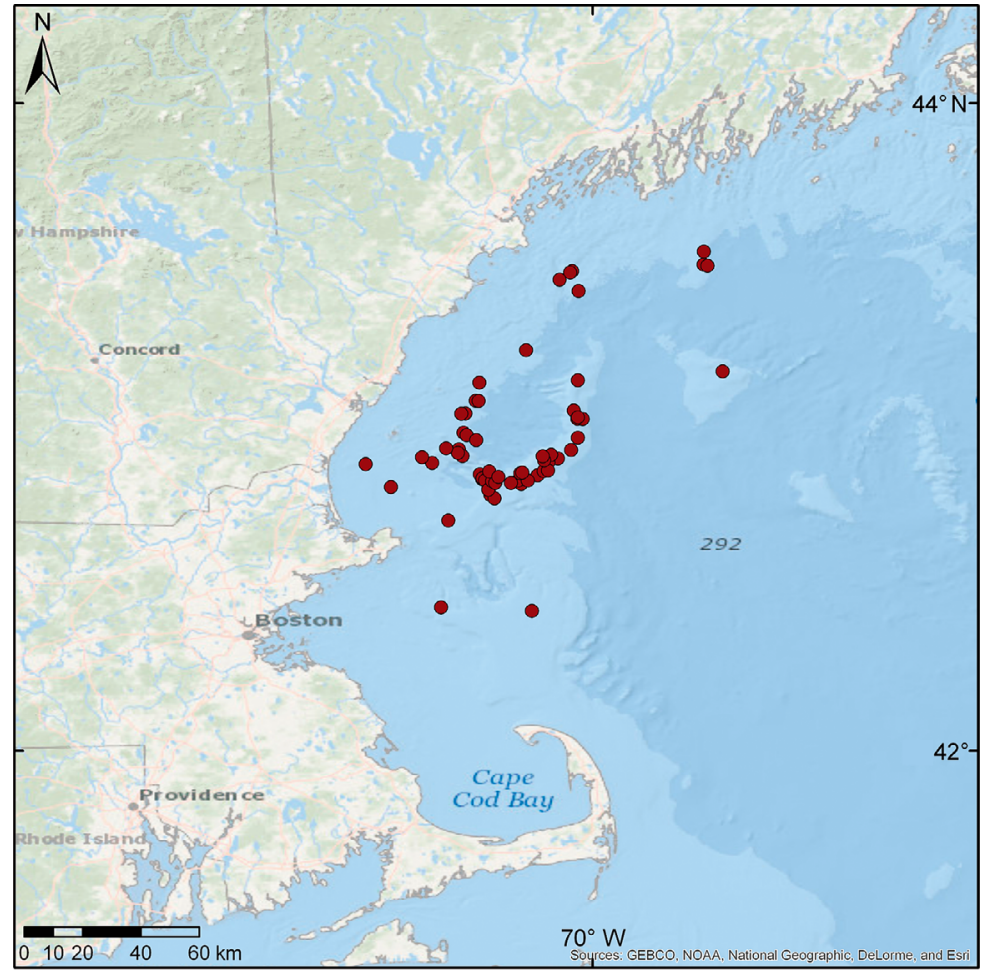

Fig. 4. Phocoena phocoena. Distribution of harbor porpoise bycatches ( $\bullet$ ) in the Gulf of Maine as documented by the National Marine Fisheries Service (NMFS) observer program between 1990 and 1994. Depth (m) shown for 1 point. Data from Northeast Fisheries Science Center, Woods Hole, Massachusetts, USA

on a monthly basis. It was also possible to estimate the cost, in terms of lost landings, if a 30 min square was closed for a particular month. This proved to be an extremely powerful tool with which to explore potential time-area closures. The GIS became the backbone of many future efforts to address the bycatch of harbor porpoises in the Gulf of Maine.

By the end of 1993, the Council was focusing its attention on the 3 areas where relatively high bycatches had been documented by the observer program. The Subgroup was particularly concerned about an area (referred to as the Z-band) adjacent to the proposed Mid-Coast closure on Jeffreys Ledge, where relatively high bycatch rates had been documented. In particular, there was concern over the potential impact of effort displaced from the MidCoast closure area to the Z-band. Conservation groups and many scientists proposed folding the Zband into the Mid-Coast closure, but, under pressure from the fishing industry, the Council agreed to leave this area open to fishing (NEFMC 1994).

A system of time-area closures, including the MidCoast (closed in November), northeast (closed from 15 August to 13 September) and Massachusetts Bay (closed in March) areas, was adopted by the Council in March 1994 as a framework adjustment to the Northeast Multispecies Fishery Management Plan. The Council hoped to reach a $20 \%$ reduction in porpoise bycatch in the first year; future management measures would be required to achieve a $60 \%$ reduction over $3 \mathrm{yr}$.

These closures were extremely unpopular with fishermen, who continued to pursue other lines of mitigation research (see 'Acoustic alarms'). An economic analysis conducted by the Council's Groundfish Plan Development Team indicated that the expected cost of this closure system to the fishery, in terms of lost landings, was approximately US $\$ 445000 \mathrm{yr}^{-1}$. This was considerably less than the estimated cost of the $4 \mathrm{~d}$ block closures initially considered by the Council, which would have entailed $>\$ 1766000$.

Adoption of these time-area closures was the first tangible conservation action taken to reduce the bycatch of harbor porpoises in the Gulf of Maine. As described below and by (Orphanides \& Palka 2013), the 3 areas were incorporated into a number of future management actions and remain part of the bycatch reduction strategy in place today. Nevertheless, they were highly unpopular with the fishing industry. There was particular concern that the closures placed an unfair burden on fishermen with small vessels who were unable to fish safely in waters far from their home ports (Murray et al. 2000). On the other side of the debate, the conservation and scientific communities worried that the closures were too small, that they excluded critical areas (such as the Z-band), and that they would simply displace effort and bycatch rather than reduce it.

\section{Acoustic alarms}

The Working Group continued to meet, exchanging information on the biology of harbor porpoises and the gillnet fishery in the Gulf of Maine. In 1991, after learning of fishermen's confusion between harbor porpoises and Atlantic white-sided dolphins Lagenorhynchus acutus, the Working Group developed a placard that differentiated these 2 species and distributed it to gillnet fishermen in the Gulf of Maine. The Working Group continued to explore potential mitiga- 
tion options, including modifications to gillnet construction and, importantly, the use of acoustic alarms to alert porpoises to the presence of a gillnet.

Gillnet fishermen had learned of the work on acoustic alarms conducted by Jon Lien from Memorial University in Canada. Lien had been working with inshore fishermen in Newfoundland to reduce collisions between humpback whales Megaptera novaeangliae and cod traps. Some whales carried off traps and others needed to be disentangled, causing costly damage to the gear. Lien knew that humpbacks used sound to communicate during the breeding season and surmised that the whales might be able to detect the gear more effectively if the traps were equipped with sound emitters. He conducted tests of sound emitters, which demonstrated promise in reducing the frequency of collisions between humpbacks and cod traps in Newfoundland (Lien et al. 1992).

Fishermen in the Gulf of Maine believed that the same concept could be applied to reduce the bycatch of harbor porpoises in their gillnets. They reasoned that sound emitters would alert porpoises to the presence of the nets and thus reduce the likelihood of entanglement. In the autumn of 1992, Roland Barnaby, a member of the Working Group, invited Lien to New Hampshire to conduct initial trials of acoustic alarms. Lien used the alarms that he had developed in Newfoundland; these devices produced a broadband sound, with a central frequency of $4 \mathrm{kHz}$, every $3 \mathrm{~s}$ at a sound pressure level of $120 \mathrm{~dB}$ re $1 \mu \mathrm{Pa} @ 1 \mathrm{~m}$. Four fishermen from New Hampshire agreed to participate in an informal trial. The alarms were the size of a soccer ball, and fishermen initially had problems attaching the alarms to their gear. Every alarm was lost from the first set of gear fished, but the fishermen attached new alarms to their gear and resumed the trial. NMFS observers monitored bycatch on all 4 vessels. By the end of the trial, 12 porpoises had been killed in control nets, and none were taken in nets equipped with alarms (J. Lien unpubl. data). The results of this trial were promising, but inconclusive because of the relatively small sample of nets fished.

In 1993, the NMFS provided funding for a more rigorous test of acoustic alarms in the autumn Gulf of Maine gillnet fishery. Fishermen redesigned the alarms to be smaller and more compatible with their gillnet gear. The new alarms produced a $2.8 \mathrm{kHz}$ sound every second, with a sound pressure level of approximately $115 \mathrm{~dB}$ re $1 \mu \mathrm{Pa} @ 1 \mathrm{~m}$. Once again, NMFS observers monitored the bycatch of porpoises and the catch of target species. The design of the 1993 experiment differed from that employed in 1992. Fishermen placed the alarms on the first 5 nets of each ex- perimental string, but added a varying number of nets without alarms to these strings. Thirty-three porpoises were taken during the experiment; all but one of these porpoises were taken in control nets (Lien et al. 1995). Interestingly, 3 porpoises were entangled in the sixth (unalarmed) net of experimental strings, suggesting that porpoises might turn into and become entangled in the first net without an alarm.

Fishermen were enthusiastic about the results of the 1993 trial and eager to adopt acoustic alarms in the gillnet fishery, particularly if this would forestall the time-area closures planned by the Council. Scientists in the Working Group were skeptical, citing flaws in the design of the experiments and raising the possibility that, even if the alarms were initially effective, porpoises would quickly habituate (or become desensitized) to the sounds they produced. This attitude reflected widespread skepticism within the broader scientific community of the efficacy of acoustic alarms (e.g. Dawson 1994). Representatives of conservation groups were also dubious, worrying that the relatively untested alarms would supplant time-area closures as the primary method of reducing bycatch in the Gulf of Maine. Fishermen were understandably frustrated by the reluctance of other members of the Working Group to endorse the use of acoustic alarms. In April 1994, after considerable debate, the Working Group asked the NMFS to hold a scientific workshop to assess the results of the 1992 and 1993 experiments and determine whether further experiments should be pursued and, if so, how they should be designed.

The NMFS convened the workshop in June 1994 in Seattle, Washington, bringing together experts in acoustics, experimental design and statistical analysis. The workshop participants drew several important conclusions (Reeves et al. 1996). First, the results of the 1992 and 1993 experiments were deemed to be inconclusive, due to problems of experimental design, particularly the mixing of 'alarmed' and 'unalarmed' nets in experimental strings. In addition, too few entanglements were observed to allow meaningful statistical conclusions to be drawn from the experiments.

Nevertheless, a simple odds-ratio analysis suggested that the risk of entanglement in nets with alarms was lower than in nets without alarms, although this difference was not statistically significant. This led the participants at the workshop to recommend further experimentation, provided that statistically sound experimental design was employed and that the sample size of entanglements was sufficient to support a rigorous statistical analysis. The participants also made a number of specific recommendations for the design of future experiments; 
these suggestions were extremely helpful in framing the next round of research.

Informed of the findings of the Seattle workshop, members of the Working Group traveled to Washington, D.C., to lobby their congressional representatives to fund a definitive test of acoustic alarms in the Gulf of Maine. Importantly, all members of the Working Group, including fishermen, scientists and representatives of conservation groups, supported the proposal. Support from such a diverse group of constituencies was a powerful factor in the decision to fund the experiment, which cost approximately $\$ 500000$ (US).

Scott Kraus of the New England Aquarium agreed to lead the experiment, which was conducted on Jeffreys Ledge between October and December 1994. Kraus assembled a team of biologists, acousticians, fishermen and statisticians to conduct the trial. Prior to the experiment, Kraus and his colleagues conducted an analysis of the statistical power required to detect a significant reduction in porpoise mortality, using data from the NMFS observer program. This analysis indicated that with 15 participating vessels, it would be possible to detect a $50 \%$ reduction in porpoise bycatch during the experimental period, given the bycatch rates observed in previous years.

Fifteen gillnet fishermen from New Hampshire and southern Maine participated in the experiment. Following the recommendations of the NMFS panel, the fishermen agreed to restrict their gear and fishing practices to certain experimental constraints. All strings were to be comprised of 12 nets, with each net constructed in a similar fashion. Fishermen were asked to retrieve the strings each day, weather permitting. NMFS observers monitored bycatch and were rotated from vessel to vessel throughout the experiment. In return for agreeing to these constraints, participating fishermen were allowed to fish in the Mid-Coast area, which was closed during November by the NEFMC. Access to this closed area was a powerful incentive for fishermen to participate in the experiment.

The experiment adopted a double-blind approach using 2 types of alarms. Both were outwardly identical, but one (active) produced an acoustic signal and the other (control) was silent. The active alarms were equipped with salt water switches that triggered upon immersion. The alarms were placed at the end of each string and at each bridle, so each string had 13 alarms, each placed $100 \mathrm{~m}$ apart. Each string was equipped with a complete set of active alarms or a set of control alarms. The choice of active or control alarms was made by a coin toss the day before the string was set.
Observers carried a new set of dry alarms aboard the vessel each day and replaced the alarms on strings of nets as they were retrieved. All alarms were changed each time the net string was retrieved. Despite many unsuccessful attempts to decipher the coding system used to identify the alarms, neither observers nor fishermen knew which alarms were active or which were controls before the string was set.

The alarms were manufactured by the Dukane Corporation and emitted a broadband signal centered at $10 \mathrm{kHz}$, with a source level of $132 \mathrm{~dB}$ re $1 \mu \mathrm{Pa}$ @ $1 \mathrm{~m}$. The alarms produced a tone that lasted for $300 \mathrm{~ms}$ and was repeated every $4 \mathrm{~s}$. The sound source level was chosen to be audible at $15 \mathrm{~dB}$ above ambient at $100 \mathrm{~m}$ (the length of $1 \mathrm{net}$ ) and to drop to ambient levels at $300 \mathrm{~m}$.

During the course of the experiment, 421 active strings and 423 control strings were set (others were deleted from the analysis because they did not conform to the required specifications). Twenty-five harbor porpoises were captured in control strings but only 2 were taken in active strings. These results demonstrated conclusively that acoustic alarms significantly reduced the bycatch of harbor porpoises in bottom-set gillnets (Kraus et al. 1997b), vindicating the fishermen who had fought for their use. The alarms caused no adverse effects on fish catches or any increase in the damage to the catch caused by seal depredation. Thus, for the first time, there was convincing evidence that acoustic alarms were a viable mitigation measure to reduce the number of harbor porpoises killed in sink gillnets in the Gulf of Maine and elsewhere.

\section{IMPLEMENTATION}

\section{MMPA re-authorization}

In April 1994 Congress re-authorized the MMPA, following a second round of negotiations between representatives of the environmental community and the fishing industry (Bache 2001). The re-authorization added Sections 117 and 118 to the Act, which included a requirement for regular assessments for each stock of marine mammals in the USA. These stock assessments must include calculation of the potential biological removal (PBR) level, the number of animals that can be removed from a population without leading to depletion or impeding recovery (Wade 1998). PBR is calculated as the product of a minimum estimate of abundance, a maximum potential rate of increase (using default values if stock- 
specific estimates are not available) and a recovery factor designed to ensure that bycatches do not impede the recovery of depleted populations. The scheme is described fully by Taylor et al. (2000).

In August 1994, the NMFS produced the first draft stock assessments required under Section 117 of the MMPA, including one for harbor porpoises in the Gulf of Maine. The minimum size of the harbor porpoise population in the Gulf of Maine was estimated to be $47200(\mathrm{CV}=0.19)$, based on surveys conducted by scientists at the NEFSC in 1991 and 1992 (Palka 1995). This population size was $>3$ times the initial estimate generated by Kraus et al. (1983).

PBR was calculated using this minimum estimate of abundance, the default value for potential rate of increase of cetaceans $(4 \%)$ and a recovery factor of 0.5 . The resulting PBR was 403 porpoises (Blaylock et al. 1995). The stock assessment also included estimates of the magnitude of bycatch derived from the NMFS observer program. The annual bycatch of porpoises from 1989 to 1993 was estimated as 1876 (CV $=0.32$ ), $>4$ times the PBR (Bravington \& Bisack 1995). This estimate was known to be negatively biased, because it did not include bycatch in Canadian gillnet fisheries of the Bay of Fundy, or mortality in the coastal gillnet fishery along the US mid-Atlantic coast. Annual estimates of harbor porpoise bycatch in the Gulf of Maine groundfish gillnet fishery and in US coastal mid-Atlantic fisheries are shown, together with estimates of PBR (Fig. 5).

\section{Council action}

In August 1995, the NMFS informed the NEFMC that the initial system of time-area closures was insufficient to reduce the bycatch of harbor porpoises in the Gulf of Maine. Furthermore, the bycatch had increased, rather than decreased, in 1994, particularly in the Mid-Coast region. The increase was, at least in part, a result of the displacement of fishing effort from closed areas into the Z-band and adjacent waters (Murray et al. 2000). The closed areas were simply neither large enough nor closed for long enough. The Marine Mammal Commission concurred, and recommended that the closures be expanded in both time and space.

In response, the Council appointed a Harbor Porpoise Review Team to examine existing conservation measures and suggest adjustments. During the next $2 \mathrm{yr}$, this review team recommended: incorporating the Z-band into the Mid-Coast closure; expanding the timing of this closure to include the period from Sep-

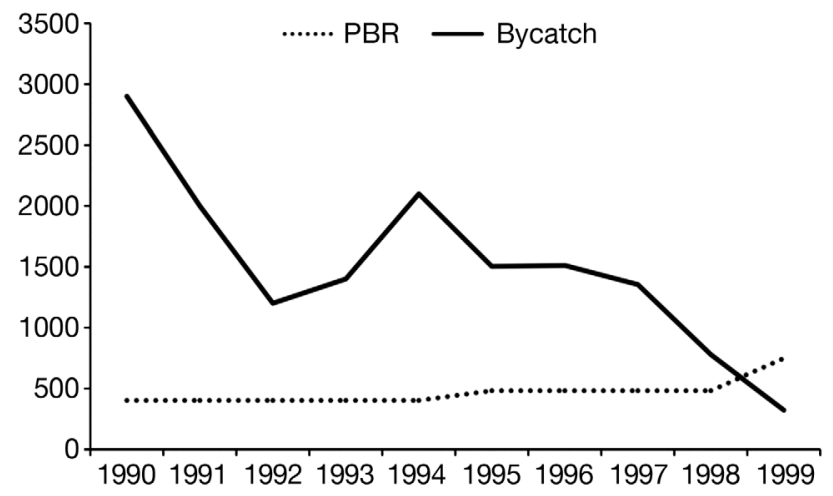

Fig. 5. Phocoena phocoena. Annual estimates of harbor porpoise bycatch and potential biological removal (PBR) levels from the US Gulf of Maine and coastal United States mid-Atlantic region from 1990 to 1999. Data were taken from annual NMFS stock assessment reports (see Waring et al. 2011)

tember to December; and additional closures in other areas, including southern New England. In addition, the review team recommended that acoustic alarms be permitted, on a limited experimental basis, in some of the areas that were otherwise closed to gillnets. The first of these 'experimental fisheries' was pursued in November and December 1996 in the Z-band near Jeffreys Ledge. Participants in the experimental fisheries agreed to use acoustic alarms that met the same specifications as the Dukane models used in the 1994 experiment. In fact, many of the same alarms were employed in the experiment and the subsequent experimental fisheries.

By the summer of 1996, the Council had adopted most of these recommendations as framework adjustments to the Northeast Multispecies Fishery Management Plan (FMP). These measures included 2 additional closures (Cape Cod South in March and the Mid-Coast in April) and authorization of an experimental fishery with acoustic alarms in the fall Mid-Coast closed area. This system of closures was part of the overall strategy to reduce fishing mortality in groundfish stocks, implemented as Amendment 7 to the FMP.

\section{Take Reduction Team}

A second important component of the 1994 reauthorization of the MMPA was the take reduction process designed to reduce the bycatch of marine mammal stocks to below PBR. The MMPA refers to stocks in which mortality exceeds PBR as strategic. For such stocks, the Secretary of Commerce must 
appoint a Take Reduction Team (TRT), which is directed to develop a plan to reduce bycatch levels to below PBR within 6 mo of the plan's implementation (Young 2001). The TRTs are comprised of representatives of fisheries in which bycatch occurs, federal agencies, coastal states, fishery management councils, environmental organizations and scientists. Meetings of TRTs are facilitated by professional mediators with experience in environmental dispute resolution, who assist the teams in working towards consensus decisions.

The Gulf of Maine harbor porpoise TRT was one of the first 2 teams formed under Section 118 of the MMPA. The TRT was convened in February 1996 and included many members of the Working Group. In addition, several members of the TRT served on the Council Harbor Porpoise Review Team. As a result, TRT members were familiar with each other and shared a long history of debate, discussion and negotiation. The TRT agreed to develop a Take Reduction Plan that would meet the ambitious goal of reducing bycatch to below PBR within 6 mo, while allocating bycatch equitably with practical measures that minimized economic impacts on the gillnet fishery (Resolve 1996).

The TRT met 5 times between February and July 1996 and, after a particularly intense negotiation during its last meeting, submitted a consensus draft plan to the NMFS on 8 August 1996. The core management plan included a series of time-area closures and additional periods when acoustic alarms would be required. The plan built on measures already implemented by the NEFMC and added additional time and area restrictions. The plan reflected tensions between fishermen, who wanted to use acoustic alarms, and environmental groups and scientists, who favored time-area closures. As a result, the draft plan was contingent on several additional measures, including: an agreement to reconvene the team 7 mo after implementation to review progress, a second acoustic alarm experiment to be held in the spring of 1997 in the Mid-Coast area, and research on the potential for habituation and displacement of harbor porpoises as a result of the use of acoustic alarms (Resolve 1996). In its negotiations, the team relied on near real-time analysis by NMFS scientists to estimate the potential benefits of each conservation measure; this quantitative analysis was absolutely critical to the success of the negotiation. Thus, despite divergent opinions regarding the validity of data used in the stock assessment process, the TRT was able to reach consensus on a plan that members viewed as imperfect but workable.
After submitting their consensus plan to the NMFS, team members waited for $>2 \mathrm{yr}$ for the NMFS to implement the plan. During this period, the only management efforts influencing harbor porpoise bycatch were developed and implemented by the Council as framework adjustments to the NEFMC Multispecies Fishery Management Plan. These actions were intended to address the conservation of severely over-fished groundfish stocks. At times, these measures undermined some of the actions taken to address harbor porpoise bycatch.

During this period, 4 experimental fisheries were implemented in which acoustic alarms were required. No porpoises were taken in 225 observed net hauls in the autumn of 1995, but unexpectedly high numbers (9 porpoises in only 88 hauls) were taken in nets equipped with alarms in an experimental fishery in the spring of 1996. Some, but not all, of this mortality was associated with failed alarms, but these results led to the concern that alarms might not be as effective as first believed. Consequently, a second full experiment, as originally recommended by the TRT, was conducted in April and May 1997. This experiment employed the original design and involved many of the same fishermen. The results were reassuring, with no porpoises caught in 180 net strings with active alarms and 11 taken in nets with control (inactive) alarms. The difference in bycatch rate was highly significant (Kraus et al. 1997a). In their report, Kraus and colleagues concluded that 'acoustic alarms will be effective in reducing the incidental catch of harbor porpoises in the sink gillnet fishery in the Gulf of Maine.'

In December 1997, the TRT re-convened and reviewed the experimental fisheries, the results of the spring experiment and observed bycatches in 1996 and 1997. They also examined the potential impact of fishery conservation measures being considered by the Council. Estimated total bycatch of harbor porpoises in 1996 was $1200(\mathrm{CV}=0.23)$, well above PBR (Fig. 5), indicating that the actions taken up to that point were insufficient. Additional mortality was still occurring in Canada (see 'Conservation measures in Canada') and in coastal fisheries along the US midAtlantic states. A separate Take Reduction Team was convened in February 1997 to deal with bycatch along the US mid-Atlantic. The Gulf of Maine TRT considered a variety of measures to further reduce mortality, including expanding the system of timearea closures and areas in which acoustic alarms would be required, but made no specific recommendations to the NMFS. 
At this point, the system was essentially broken. The NEFMC was struggling to find ways to conserve depleted groundfish stocks without destroying the fishery; considerations of harbor porpoise bycatch had faded into the background. The TRT process was stalled because the NMFS had not published or implemented final regulations. So, in August 1998, 2 yr after the original Take Reduction Plan had been submitted, several environmental groups, led by the Center for Marine Conservation, filed suit in US District Court to compel the NMFS to publish and implement a Take Reduction Plan (Young 2001). A settlement was reached in which the NMFS agreed to publish a final Take Reduction Plan for Gulf of Maine harbor porpoises in December 1998. The final rule included most of the conservation measures initially recommended by the TRT (NMFS 1998). The resulting management plan was complex, especially when overlaid onto relevant measures from the Council's FMP (Fig. 6).

\section{Conservation measures in Canada}

In the summers of 1993 and 1994, the Canadian DFO instituted an observer program in the gillnet fishery in the Bay of Fundy. Observed porpoise bycatch rates were higher than those observed in the Gulf of Maine, but total mortality was less because fishing effort was relatively low. Total bycatch was estimated to be 424 in 1993 and 101 in 1994 (Trippel et al. 1996). Jon Lien conducted trials of acoustic alarms in the Bay of Fundy in 1995 using the same devices that had been employed in the Gulf of Maine in 1993 (Lien et al. 1995). The trials were successful, with a significant reduction in the number of porpoises captured in nets equipped with alarms (Whale Research Group 1996 unpubl. data). Further field tests were conducted in 1996 and 1997 using Dukane alarms (Trippel et al. 1999). Porpoise bycatch rates were reduced significantly in these trials, by 68 and $85 \%$ in 1996 and 1997, respectively.

While these trials were being conducted, the DFO was consulting with the NMFS regarding co-operative measures that might be taken to reduce the bycatch of this trans-boundary stock. In 1994, the DFO produced a draft Conservation Plan for harbor porpoises in the Bay of Fundy, which contained a series of research, consultation and management measures. The Conservation Plan included a provision to close an area of the western Bay of Fundy to gillnet fishing effort if 'a high incidence of incidental catch is observed' (DFO 1994). However, the Conser- vation Plan failed to identify a target goal (comparable to PBR), or to identify what level of bycatch would trigger the area closure.

Despite the existence of the Conservation Plan and the successful trials of acoustic alarms, the DFO has never taken any management action to reduce the bycatch of harbor porpoises in Canadian gillnet fisheries in the Bay of Fundy. Like its counterpart in the USA, the Canadian gillnet fishery has dwindled in size in recent years. Nevertheless, harbor porpoises continue to be killed in Canadian gillnets each year, albeit in unknown numbers because they are no longer monitored by an observer program.

\section{MONITORING}

The annual bycatch of harbor porpoises in the Gulf of Maine gillnet fishery fell below PBR for the first time in 1999. This coincided with implementation of the Take Reduction Plan, although many conservation measures had been put into place prior to this time. The combination of time-area closures and acoustic alarms reduced porpoise bycatch in the Gulf of Maine to $<300 \mathrm{yr}^{-1}$, with additional animals taken along the US mid-Atlantic coast (Fig. 5).

While the NEFMC and TRT were developing management measures, the NMFS deferred action on its proposal to list the harbor porpoise as threatened under the ESA (NMFS 1993). By 1999 an effective bycatch reduction program was in place, reducing mortality below PBR. A population viability analysis (PVA) indicated that mortality levels below PBR would not lead to a measurable probability of extinction within $100 \mathrm{yr}$ (NMFS 1993). The NMFS finally determined, therefore, that an ESA listing was not warranted (NMFS 1999, 2001).

The story continued, of course, after implementation of the Take Reduction Plan in 1999; these more recent developments are described by Orphanides \& Palka (2013).

\section{CONCLUSIONS}

Thirty years have passed since Jim Gilbert and Kate Wynne began their pioneering research into interactions between marine mammals and commercial fisheries in the Gulf of Maine. During these 3 decades the bycatch of harbor porpoises evolved into one of the most serious marine mammal conservation issues in the USA. A large number of fishermen, scientists, environmentalists and fisheries managers 
worked to develop, refine and implement a suite of measures to reduce the bycatch of this species from almost $3000 \mathrm{yr}^{-1}$ to a sustainable level (Fig. 5), although bycatch has recently increased once again (Orphanides \& Palka 2013). What can we learn from this case study?

First, the existence of a clear conservation goal has been critical to management efforts in the USA. Fishermen may dislike the concept of PBR, or believe that it is too conservative (risk-averse), but they understand it. The information used to calculate PBR is readily available to all interested parties through the NMFS stock assessment process. The observer program provides annual estimates of bycatch that can be measured against the standard of PBR. The process is transparent, and it is immediately clear to all stakeholders whether management practices are sufficient to reduce bycatches below PBR. The data used in the stock assessment are far from perfect, but they improve continually as science progresses. The PBR goal is articulated clearly within the MMPA, and it is important that management actions, such as convening a Take Reduction Team, are required (not merely recommended) when the goal is not met.

The contrasting management approaches taken in Canada and the USA are also instructive in this regard. Porpoises are taken as bycatch in gillnet fisheries in both the USA and Canada. In the USA, the MMPA mandates that bycatches should not have an adverse impact on the population. In Canada, despite the existence of a Conservation Plan, no management action has ever been taken to address the bycatch of harbor porpoises. Experiments with acoustic alarms in the Bay of Fundy demonstrated a significant reduction in bycatch rate, but alarms have never been required in the Canadian fishery. In a similar vein, a potential closure area was identified in the Conservation Plan, but never implemented. The lack of specific management goals and the absence of a strong legislative mandate have precluded management action in Canada.

Not all of the goals of the MMPA have been met in the Gulf of Maine. The MMPA requires commercial fisheries to reduce the incidental mortality of marine mammals to insignificant levels approaching a zero rate. This requirement is commonly referred to as the zero mortality rate goal (ZMRG). The NMFS has interpreted the zero mortality rate to be $10 \%$ of PBR (NMFS 2004). Due to the difficulty of achieving PBR and maintaining mortality below this initial threshold, there has been little focus on achieving a zero mortality rate in the Gulf of Maine.
The second major lesson from the Gulf of Maine is the importance of adequate information. Actions taken by the Council and TRT were driven by data on bycatch and landings provided by scientists and managers from the NMFS. Particularly important in this regard were observations from the observer program, which confirmed the existence of a large bycatch early in the process. During the TRT negotiations, NMFS scientists estimated the benefit (in terms of bycatch reduction) and costs (lost fishing opportunities) of potential management measures almost as they were generated. When combined with a quantitative goal (PBR), this allowed stakeholders to evaluate different mitigation measures and to offer suggestions for compromise, substitution, or alteration.

Third, collaboration among stakeholders was a critical component of conservation efforts. The early discussions within the Working Group were particularly important in setting the stage for future collaborative efforts. The consensus achieved within this informal group of fishermen, scientists, managers and environmentalists was a powerful force in securing funding for the 1994 acoustic alarm experiment. Later negotiations within the TRT led to a consensus plan that was able to reduce bycatches to below PBR by 1999. TRT members are seldom completely satisfied with the outcome of their negotiations, but they believe that the process is an effective means of decision making (Resolve 1999). In particular, I would like to emphasize the importance of collaboration (despite frequent disagreements, arguments and a few long-running battles) between scientists and fishermen when working towards solutions. This was particularly important with the development and testing of acoustic alarms. Fishermen pushed hard for the development of this mitigation tool, even in the face of skepticism from the scientific community. In turn, scientists ensured that trials were designed and implemented carefully, so as to maximize the information generated during such experiments.

The final lesson is the importance of monitoring, especially after mitigation measures have been implemented. Management agencies began to address this issue only after the NMFS observer program had documented the existence of large bycatches in the early 1990s. The availability of independent, credible and unbiased estimates of bycatch was critical to spurring management action and engaging the fishing industry in the search for solutions. As mitigation measures began to be implemented, the observer program allowed evaluation of their success or failure. It was possible to modify the boundaries of time- 
area closures by examining data generated by the observer program.

Such monitoring programs will be particularly important in cases like this one, in which mitigation measures are expensive, unpopular, or both. Despite their initial popularity, fishermen were not keen to purchase acoustic alarms for their gillnets and did not want to be excluded from preferred fishing areas. Both mitigation measures created added costs to their fishing practices. The monitoring program, backed by enforcement activities, is critical to ensuring compliance. This is an important lesson for all cases in which costly or unpopular mitigation measures must be implemented.

Acknowledgements. I thank the following individuals for helping to refine my thinking about harbor porpoises and gillnet fisheries in the Gulf of Maine: Erik Andersen, Per Berggren, Tara Cox, Jerry Conway, Patricia Fiorelli, David Gaskin, Ron Kastelein, Scott Kraus, David Lavigne, Jon Lien, Bob MacKinnon, Richard Merrick, Kimberly Murray, John Nicolas, Simon Northridge, Debi Palka, Mike Payne, David Potter, Randall Reeves, Tim Smith, Ron Smolowitz, Karen Steuer, Ed Trippel, Kim Urian, Paul Wade, Dave Wiley, John Williamson and Sharon Young. Many of these individuals were members of the New England Harbor Porpoise Working Group. My work on harbor porpoises has been supported by: the Department of Fisheries and Oceans, National Marine Fisheries Service, Marine Mammal Commission, National Fish and Wildlife Foundation, World Wildlife Fund Canada, Whale and Dolphin Conservation Society, Humane Society of the United States, International Fund for Animal Welfare and Office of Naval Research. I thank Tara Cox, Danielle Waples, several anonymous reviewers and Randall Reeves, for improving the manuscript with helpful comments, and Heather Foley for preparing Fig. 2.

\section{LITERATURE CITED}

Bache SJ (2001) A primer on take reduction planning under the Marine Mammal Protection Act. Ocean Coast Manag 44:221-239

Barlow J, Boveng P (1991) Modeling age-specific mortality for marine mammal populations. Mar Mamm Sci 7:50-65

Blaylock RA, Hain JW, Hansen LJ, Palka DL, Waring GT (1995) U.S. Atlantic and Gulf of Mexico marine mammal stock assessments. NMFS-SEFSC-363, NOAA Technical Memorandum, Washington, DC

Bravington MV, Bisack KD (1995) Estimates of harbour porpoise bycatch in the Gulf of Maine sink gillnet fishery. Rep Int Whal Comm 47:1-8

Burrowes TR (1988) Reauthorizing the Marine Mammal Protection Act: purposes, porpoises and proposals - an east coast perspective. Territorial Sea 8:9-19

Collins JW (1886) Gillnets in the cod fishery: a description of Norwegian cod-nets, etc., and a history of their use in the United States. Part XII, Report of the U.S. Fisheries Commission for 1884, Washington, DC, p 265-285

Dawson SM (1994) The potential for reducing entanglement of dolphins and porpoises with acoustic modifications to gillnets. Rep Int Whal Comm Spec Issue 15:573-578

Department of Fisheries and Oceans (1994) Harbour porpoise conservation plan for the Bay of Fundy. DFO, Ottawa

Dobbs D (2000) The great gulf: fishermen, scientists, and the struggle to revive the world's greatest fishery. Island Press, Washington, DC

Gannon DP, Craddock JE, Read AJ (1998) Autumn diet of harbor porpoises (Phocoena phocoena) in the Gulf of Maine. Fish Bull 96:428-437

Gaskin DE (1984) The harbour porpoise Phocoena phocoena (L.): regional populations, status, and information on direct and indirect catches. Rep Int Whal Comm 34: 569-586

Gaskin DE (1992) Status of the harbour porpoise, Phocoena phocoena, in Canada. Can Field Nat 106:36-54

Gilbert JR, Wynne KM (1988) Harbor seal populations and fisheries interactions with marine mammals in New England. Final report, Contract NA-EA-C-0070, Northeast Fisheries Science Center, Woods Hole, MA

Hoyt E (1989) New England's harried harbor porpoise. Defenders 64:10-17

International Whaling Commission (1991) Report of the subcommittee on small cetaceans. Rep Int Whal Comm 41: 172-190

Jefferson TA, Curry BE (1994) A global review of porpoise (Cetacea: Phocoenidae) mortality in gillnets. Biol Conserv 67:167-183

Kraus SD, Prescott JH, Stone GS (1983) Harbor porpoise, Phocoena phocoena, in the U.S. coastal waters of the Gulf of Maine: a survey to determine seasonal distribution and abundance. Contract Report NA-FA-C-00027, Northeast Fisheries Science Center, Woods Hole, MA

Kraus SD, Brault S, Baldwin K (1997a) A field test of the use of pingers to reduce incidental mortality of harbor porpoises in gillnets. Paper SC/49/SM42 presented to the Scientific Committee of the International Whaling Commission. IWC, Cambridge

Kraus SD, Read AJ, Anderson E, Baldwin K, Solow A, Spradlin T, Williamson J (1997b) Acoustic alarms reduce porpoise mortality. Nature 388:525

> Lear WH, Christensen O (1975) By-catches of harbour porpoise (Phocoena phocoena) in salmon drift nets at West Greenland. J Fish Res Board Can 32:1223-1228

Lien J, Barney W, Todd S, Seton R (1992) Effects of adding sounds to cod traps on the probability of collisions by humpback whales. In: Thomas JA, Kastelein RA, Supin AY (eds) Marine mammal sensory systems. Plenum Press, New York, NY, p 701-708

Lien J, Hood C, Pittman D, Ruel P and others (1995) Field tests of acoustic devices on groundfish gillnets: assessment of effectiveness in reducing harbour porpoise bycatch. In: Kastelein RA, Thomas JA, Nachtigall PE (eds) Sensory systems of aquatic mammals. De Spil Publishers, Woerden, p 349-364

Marine Mammal Commission (1992) Annual report to congress - 1991. Available at: http://mmc.gov/reports/ annual/ (accessed 7 May 2013)

Murray KT, Read AJ, Solow AR (2000) The use of time/area closures to reduce by-catches of harbour porpoises: lessons from the Gulf of Maine sink gillnet fishery. J Cetacean Res Manag 2:135-141

NEFMC (New England Fishery Management Council) (1994) Final Framework Adjustment \#4 to the Northeast 
Multispecies Fishery Management Plan to reduce the bycatch of harbor porpoise in the Gulf of Maine sink gillnet fishery. NEFMC, Saugus, MA

NEFSC (Northeast Fisheries Science Center) (1994) Estimating harbor porpoise bycatch in the Gulf of Maine sink gillnet fishery. Reference Document 94-24, NEFSC, Woods Hole, MA

NMFS (National Marine Fisheries Service) (1991) Endangered and threatened species. Review of the status of harbor porpoise. Fed Regist 56:65044-65045

NMFS (National Marine Fisheries Service) (1992) Harbor porpoise in eastern North America: status and research needs. Reference Document 92-06, NEFSC, Woods Hole, MA

NMFS (National Marine Fisheries Service) (1993) Proposed listing of Gulf of Maine population of harbor porpoises as threatened under the Endangered Species Act. Fed Regist 58:3108-3120

NMFS (National Marine Fisheries Service) (1998) Taking of marine mammals incidental to commercial fishing operations; harbor porpoise take reduction plan regulations. Fed Regist 63:66464-66490

NMFS (National Marine Fisheries Service) (1999) Listing of Gulf of Maine/Bay of Fundy population of harbor porpoise as threatened under the Endangered Species Act. Fed Regist 64:465-471

NMFS (National Marine Fisheries Service) (2001) Status review of the Gulf of Maine/Bay of Fundy population of harbor porpoise under the Endangered Species Act (ESA). Fed Regist 66:53195-53197

NMFS (National Marine Fisheries Service) (2004) Authorization for commercial fisheries under the Marine Mammal Protection Act of 1972; zero mortality rate goal. Fed Regist 69:43338-43345

Orphanides C, Palka DL (2013) Analysis of harbor porpoise gillnet bycatch, compliance, and enforcement trends in the US northwestern Atlantic, January 1999 to May 2010. Endang Species Res 20:251-270

Palka D (1995) Abundance estimate of the Gulf of Maine harbor porpoise. Rep Int Whal Comm Spec Issue 16:27-50

Palka DL, Read AJ, Westgate AJ, Johnston DW (1995) Summary of current knowledge of harbour porpoises in U.S. and Canadian Atlantic waters. Rep Int Whal Comm 46: 559-565

Pauly D, Maclean JL (2003) In a perfect ocean: the state of fisheries and ecosystems in the North Atlantic Ocean. Island Press, Washington, DC

Polacheck T (1989) Harbor porpoises and the gillnet fishery. Oceanus 32:63-70

Read AJ (1990) Age at sexual maturity and pregnancy rates of harbour porpoises Phocoena phocoena from the Bay of Fundy. Can J Fish Aquat Sci 47:561-565

Read AJ (1999) Harbour porpoise-Phocoena phocoena (Linnaeus, 1758). In: Ridgway SH, Harrison RJ (eds) Handbook of marine mammals, Vol 6. Academic Press, New York, NY, p 323-355

Editorial responsibility: Randall Reeves, Hudson, Quebec, Canada
Read AJ (2010) Conservation biology. In: Boyd IL, Bowen WD, Iverson SJ (eds) Marine mammal ecology and conservation. Oxford University Press, Oxford, p 340-359

Read AJ, Gaskin DE (1988) Incidental catch of harbor porpoises by gillnets. J Wildl Manag 52:517-523

Read AJ, Westgate AJ (1997) Monitoring the movements of harbour porpoises (Phocoena phocoena) with satellite telemetry. Mar Biol 130:315-322

Reeves RR, Hofman RJ, Silber GK, Wilkinson D (1996) Acoustic deterrence of harmful marine mammal-fishery interactions: proceedings of a workshop held in Seattle, Washington, 20-22 March 1996. NOAA Tech Memo NMFS-OPR-10

Resolve (1996) Gulf of Maine/Bay of Fundy harbor porpoise Take Reduction Team Take Reduction Plan. Resolve, Inc., Washington, DC

Resolve (1999) The National Marine Fisheries Service Take Reduction Team negotiation process evaluation. Contract Report 50-DGNF-5-00164, National Marine Fisheries Service, Silver Spring, MD

Rosel PE, France SF, Wang JY, Kocher TD (1999) Genetic structure of harbour porpoise Phocoena phocoena populations in the Northwest Atlantic based on mitochondrial and nuclear markers. Mol Ecol 8:S41-S54

Smith TD, Palka D, Bisack K (1991) Preliminary estimates of harbor porpoise abundance and by-catch. Reference Document 91-04, Northeast Fisheries Science Center, Woods Hole, MA

Taylor BL, Wade PR, DeMaster DP, Barlow J (2000) Incorporating uncertainty into management models for marine mammals. Conserv Biol 14:1243-1252

Trippel EA, Wang JY, Strong MB, Carter LS, Conway JD (1996) Incidental mortality of harbour porpoise (Phocoena phocoena) by the gillnet fishery in the lower Bay of Fundy. Can J Fish Aquat Sci 53:1294-1300

Trippel EA, Strong MB, Terhune J, Conway JD (1999) Mitigation of harbor porpoise (Phocoena phocoena) by-catch in the gillnet fishery in the lower Bay of Fundy. Can J Fish Aquat Sci 56:113-123

- Wade PR (1998) Calculating limits to the human-caused mortality of cetaceans and pinnipeds. Mar Mamm Sci 14: $1-37$

Waring GT, Josephson E, Maze-Foley K, Rosel PE (eds) (2011) U.S. Atlantic and Gulf of Mexico marine mammal stock assessments-2009. NOAA Tech Memo NMFSNE-219

> Westgate AJ, Read AJ, Berggren P, Koopman HN, Gaskin DE (1995) Diving behaviour of harbour porpoises, Phocoena phocoena. Can J Fish Aquat Sci 52:1064-1073

- Woodley TH, Read AJ (1991) Potential rates of increase of a harbour porpoise Phocoena phocoena population subjected to incidental mortality in commercial fisheries. Can J Fish Aquat Sci 48:2429-2435

Young N (2001) The conservation of marine mammals using a multi-party approach: an evaluation of the Take Reduction Team process. Ocean Coast Law J 6:293-346

Submitted: May 24, 2012; Accepted: December 12, 2012 Proofs received from author(s): May 7, 2013 